\title{
Bleaching internal untuk merawat perubahan warna gigi insisivus sentralis kanan atas (Laporan Kasus) Internal bleaching as a treatment to color-changed of right upper centralis canine (case report)
}

\author{
${ }^{1}$ Firsta Dianty, ${ }^{2}$ Endang Sukartini, ${ }^{2}$ Milly Armilia \\ ${ }^{1}$ Peserta PPDGS Konservasi Gigi \\ ${ }^{2}$ Bagian Konservasi Gigi \\ Fakultas Kedokteran Gigi Universitas Padjajaran \\ Bandung, Indonesia
}

\begin{abstract}
Intracoronal bleeding in the tooth pulp due to trauma is one of the causes of tooth discoloration. Anterior tooth discoloration often cause esthetic problem that affect individual perfomance. Internal bleaching is a non-vital bleaching method performed after endodontic treatment using strong oxidator agent in pulp chamber. This case report discusses about internal bleaching treatment with walking bleach technique on tooth 11 after endodontic treatment. Concentration of hidrogen perokxide 35\% was applied for 3-7 days, this procedure was repeated until the tooth color was gained. The tooth color was accomplished in second visit. As conclusion is internal bleaching as treatment of tooth discoloration due to trauma can provide a good result with good endodontic treatment.
\end{abstract}

Key words: discoloration, internal bleaching, walking bleach, hydrogen peroxide

\section{ABSTRAK}

Perdarahan intrakoronal pada pulpa gigi karena trauma merupakan salah satu penyebab perubahan warna pada gigi. Pada gigi anterior, perubahan warna seringkali menimbulkan masalah estetik yang akan mempengaruhi penampilan seseorang. Bleaching internal merupakan metode pemutihan pada gigi non vital setelah dilakukan perawatan endodontik, dengan cara meletakkan bahan oksidator kuat ke dalam kamar pulpa. Dalam laporan kasus ini dibahas mengenai perawatan bleaching internal dengan teknik walking bleach pada gigi 11 setelah perawatan endodontik akibat trauma. Hidrogen peroksida dengan konsentrasi 35\% diaplikasikan selama 3-7 hari, prosedur diulang hingga mencapai warna yang diinginkan. Pada kasus ini warna gigi sudah dapat dicapai pada kunjungan yang kedua. Dapat disimpulkan bahwa bleaching internal dapat memperbaiki perubahan warna gigi akibat trauma pada masa lampau dengan hasil yang memuaskan dengan asumsi perawatan endodontiknya adekuat.

Kata kunci: perubahan warna, bleaching internal, walking bleach, hidrogen peroksida

Koresponden: Firsta Dianty, Peserta PPDGS Konservasi Gigi, Fakultas Kedokteran Gigi Universitas Padjajaran, Bandung, Indonesia. E-mail: firstadianty@yahoo.com

\section{PENDAHULUAN}

Perubahan warna pada gigi terutama gigi anterior sangat mempengaruhi estetik dan penampilan seseorang. Tuntutan estetik inilah yang memotivasi pasien untuk mencari upaya perbaikan.

Perubahan warna pada gigi dapat bersifat ekstrinsik maupun intrinsik, dapat terjadi pada gigi vital atau non vital. Keadaan ini dapat diperbaiki dengan berbagai cara, misalnya pembuatan mahkota, veneer dan bleaching. ${ }^{1}$ Pada beberapa keadaan klinis tertentu, prosedur bleaching dapat dilakukan sebagai alternatif yang non invasif dibandingkan dengan pembuatan restorasi. ${ }^{2}$ Prosedur bleaching dapat dilakukan secara internal pada gigi non vital maupun eksternal untuk gigi vital. Bleaching internal merupakan metode perawatan perubahan warna pada gigi non vital yang sudah dilakukan perawatan saluran akar dengan meletakkan bahan oksidator kuat dalam kamar pulpa.

Pada laporan kasus ini dibahas mengenai bleaching internal dengan tehnik walking bleach pada gigi insisivus sentral kanan rahang atas setelah dilakukan perawatan saluran akar pasca trauma kurang lebih 23 tahun yang lalu.

\section{KASUS}

Seorang perempuan berusia 35 tahun rujukan dari sejawat datang di Klinik Spesialis Konservasi Gigi RSGM Bandung, No.CMKG 000873. Pasien ingin dirawat gigi depannya karena terjadi perubahan warna.

Dari anamnesis diketahui pasien mempunyai riwayat mengalami benturan kurang lebih 23 tahun yang lalu, saat pasien berusia 12 tahun. Satu bulan yang lalu telah selesai dilakukan perawatan saluran akar pada gigi 11 . 


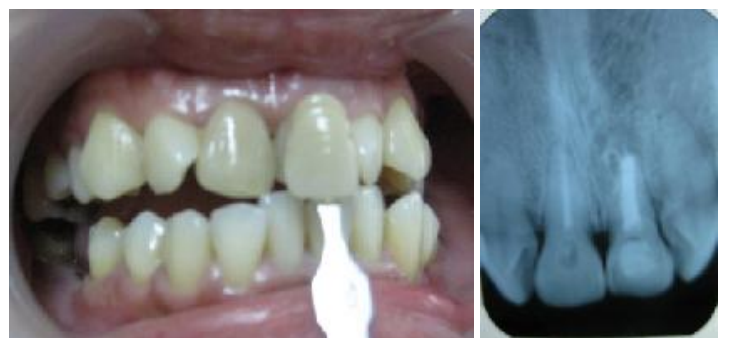

Gambar 1. Foto diagnosis dan gambaran radiologis periapikal gigi 11 .

Pemeriksaan radiografis memperlihatkan pengisian saluran akar yang hermetis, membran periodontal dan jaringan periapikal tidak ada kelainan. Pemeriksaan klinis sondasi (-), perkusi $(-)$, palpasi (-), mobilitas (-), warna gigi 11 adalah A4 (gambar 1).

Diagnosis gigi 11 adalah non vital dengan diskolorasi dan telah dilakukan perawatan saluran akar. Rencana perawatan bleaching internal dengan tehnik walking bleach dan restorasi akhir tambalan kelas I di foramen caecum dengan komposit.

\section{PENATALAKSANAAN KASUS}

Sebelum prosedur bleaching dilakukan, pasien diberi penjelasan mengenai penyebab perubahan warna pada giginya, prosedur yang akan dilakukan, dan kemungkinan hasil yang diharapkan.

Pada kunjungan pertama, permukaan gigi dibersihkan dari seluruh debris dan plak agar dapat diperoleh warna gigi yang sesungguhnya. Setelah itu warna gigi ditentukan dengan menggunakan shade guide Vita Lumin Vacuum yaitu A4 dan dilakukan foto awal yang akan digunakan sebagai ukuran keberhasilan hasil perawatan bleaching dan sebagai pembanding. Selanjutnya ditentukan dan diukur letak kedalaman epithel attachment menggunakan probe periodontal (gambar 2).
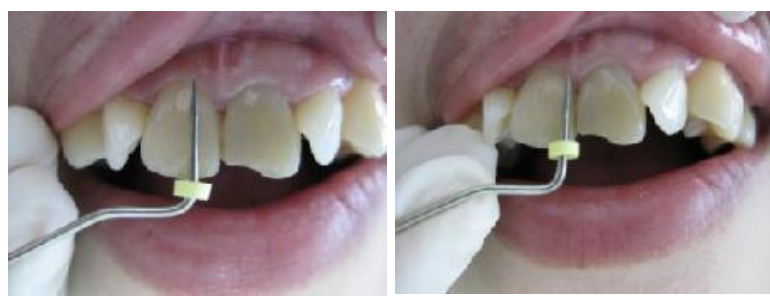

Gambar 2. Menentukan dan mengukur letak kedalaman barier pada bagian labial, mesial dan distal.

Daerah kerja diisolasi, kemudian tumpatan pada kavitas akses dibongkar, lalu bahan pengisi saluran akar dikeluarkan sampai kedalaman 1-2 $\mathrm{mm}$ di bawah CEJ. Aplikasikan pelapis servikal dengan glass ionomer setebal $2 \mathrm{~mm}$ membentuk sayap, di atas gutta perca, dengan bentuk dasar melandai ke arah labial. Selanjutnya kavitas dibersihkan, kemudian aplikasikan bahan pemutih (opalescence endo, ultradent) dengan menggunakan kapas butir. Setelah itu kavitas ditutup dengan glass ionomer dan pasien diinstruksikan untuk datang kembali setelah 1 minggu.

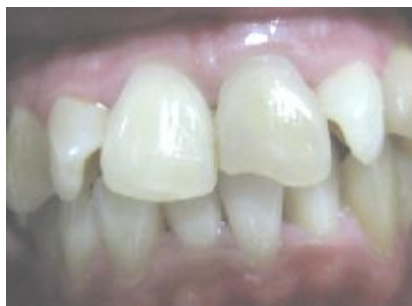

Gambar 4. Warna gigi sudah terlihat berubah pada kunjungan kedua.

Pada kunjungan kedua, pemeriksaan pada gigi tidak menunjukkan adanya kelainan jaringan lunak, tes perkusi (-), tekan (-). Sudah terlihat adanya perubahan warna pada gigi (gambar 4). Tambalan sementara dibuka, bahan bleaching dibuang serta kavitas diirigasi dengan akuades steril. Aplikasikan kembali bahan bleaching dan pasien diinstruksikan untuk kembali 1 minggu kemudian.

Pada kunjungan ketiga, pemeriksaan perkusi $(-)$, tekan (-), serta tidak ada keluhan dari pasien. Warna gigi sudah sesuai dengan gigi sebelah kanan (gambar 5) dan pasien sudah merasa puas. Tambalan sementara dibuka, bahan bleaching dikeluarkan, serta kavitas dibersihkan. Selanjutnya kavitas tutup kembali dengan tambalan sementara. Pemotretan akhir dilakukan untuk melihat perubahan warna yang terjadi.

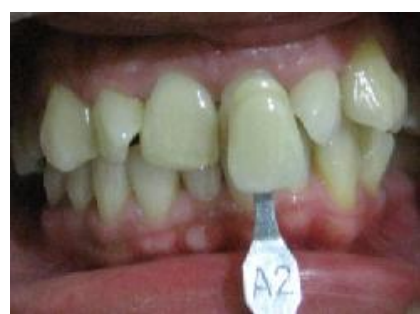

Gambar 5. Kunjungan ketiga, warna gigi menjadi A2.

Pada kunjungan terakhir dilakukan kontrol pada gigi 11. Tidak ada keluhan dari pasien; tes palpasi (-), perkusi (-) dan tekan (-). Tambalan 
sementara dibuka, kavitas diirigasi, dikeringkan, dan selanjutnya dilakukan penambalan menggunakan resin komposit pada foramen caecum

\section{PEMBAHASAN}

Penyebab perubahan warna secara umum dibagi atas ekstrinsik dan intrinsik, tergantung lokasi dan etiologi. Perubahan warna yang terlihat pada gigi non vital terutama disebabkan oleh degenerasi pulpa akibat trauma. Dapat juga karena perawatan saluran akar yang tidak sempurna karena sisa-sisa jaringan pulpa masih ada. Selain itu karena kurangnya irigasi pada waktu preparasi biomekanis ataupun preparasi akses yang tidak sempurna dapat menyebabkan diskolorasi pada gigi. Diagnosis yang benar mengenai penyebab perubahan warna sangat penting, karena berpengaruh pada hasil perawatan. ${ }^{1}$

Pada kasus ini perubahan warna terjadi pada gigi 11 dan 21, dengan derajat perubahan warna yang berbeda. Kemungkinan hal ini disebabkan trauma tidak langsung mengenai gigi 11. Pasien terjatuh dari sepeda semasa kecil dan setelah 23 tahun baru dilakukan perawatan saluran akar karena tidak ada keluhan.

Trauma yang mengenai struktur gigi menyebabkan pecahnya pembuluh darah kapiler dalam kamar pulpa dan terjadi perdarahan. Darah atau komponen darah yang menggenangi kamar pulpa masuk ke dalam tubuli dentin secara difusi, kemudian sel-sel darah merah mengalami proses hemolisis dengan melepaskan hemoglobin. Hemoglobin selanjutnya mengalami proses degradasi dan melepaskan komponen besi. Komponen besi bersenyawa dengan hidrogen sulfida yang merupakan produk bakteri, menghasilkan senyawa feric sulfat berwarna hitam yang kemudian mengadakan penetrasi ke dalam tubuli dentin menyebabkan perubahan warna pada mahkota gigi. Jika pulpanya menjadi nekrosis, perubahan warna biasanya menetap., ${ }^{2,3}$

Bahan pemutih yang digunakan hidrogen peroksida $\left(\mathrm{H}_{2} \mathrm{O}_{2}\right) 35 \% . \mathrm{H}_{2} \mathrm{O}_{2}$ berbentuk cairan jernih, tidak berbau, tidak stabil dan bersifat asam. $\mathrm{H}_{2} \mathrm{O}_{2}$ mempunyai berat molekul yang rendah sehingga dapat berdifusi ke email dan dentin. Proses bleaching berdasarkan reaksi oksidasireduksi. Pada reaksi redoks, bahan $\mathrm{H}_{2} \mathrm{O}_{2}$ sebagai oksidator akan melepaskan radikal bebas yang tidak mempunyai pasangan elektron. Elektron ini berikatan dengan molekul organik untuk mencapai kestabilan, yaitu daerah yang memiliki banyak ikatan ganda dan memutuskan ikatan tersebut menjadi lebih sederhana yang memberikan warna yang lebih terang. ${ }^{1,4}$

$\mathrm{H}_{2} \mathrm{O}_{2}$ mampu menghasilkan radikal bebas dengan reaksi $\mathrm{H} 2 \mathrm{O} 2 \rightarrow \mathrm{HO}_{2}{ }^{*}+\mathrm{O}^{*}$. $\mathrm{HO}_{2}{ }^{*}$ (perhidroksil) merupakan radikal bebas yang sangat reaktif sedangkan $\mathrm{O}^{*}$ (nascent oxygen) adalah radikal bebas yang kurang reaktif. Agar dapat dihasilkan ion $\mathrm{HO}_{2}{ }^{*}$ diperlukan $\mathrm{pH}$ basa antara $9,5-10,8{ }^{1}$

Teknik walking bleach lebih disukai karena waktu yang diperlukan lebih singkat, aman serta nyaman bagi pasien. Prosedurnya tidak invasif karena tidak banyak mengambil jaringan keras gigi. ${ }^{3,5,6}$

Beberapa hal yang perlu diperhatikan sebelum melakukan bleaching internal diantaranya kualitas pengisian saluran akar harus adekuat, gunakan pelapis servikal untuk mencegah masuknya bahan bleaching ke dalam saluran akar ataupun ke ligamen periodontal. Rotstein dkk, menunjukkan bahwa penggunaan glass ionomer setebal $2 \mathrm{~mm}$ dapat mencegah penetrasi $30 \% \mathrm{H}_{2} \mathrm{O}_{2}$ ke dalam saluran akar. Selain itu, setelah perawatan selesai dapat berfungsi sebagai dasar restorasi akhir. Pembuatan pelapis servikal dengan cara mengurangi gutta perca sedalam 1-2 $\mathrm{mm}$ di bawah CEJ. Untuk menentukan kedalaman dapat digunakan probe periodontal yang dimasukkan ke dalam kamar pulpa. Kavitas harus bebas debris dan sisa-sisa bahan pengisi, karena akan mempengaruhi efektivitas bahan bleaching. ${ }^{7}$

Penambalan gigi dengan komposit dilakukan 1-3 minggu kemudian, karena adanya sisa $\mathrm{H}_{2} \mathrm{O}_{2}$ akan menghambat polimerisasi komposit dan mengurangi kekuatan ikat terhadap email. Berkurangnya kekuatan ikat bersifat sementara karena akan berkurang dalam waktu 24 jam, dan hilang setelah 1 minggu. ${ }^{1,8}$

\section{SIMPULAN}

Perawatan bleaching internal dengan teknik walking bleach pada diskolorasi akibat trauma memberikan hasil yang memuaskan, aman dan ekonomis untuk memenuhi kebutuhan estetik pasien.

\section{SARAN}

Ketelitian dokter gigi sangat diperlukan dalam prosedur bleaching internal ini, karena keberhasilan bleaching internal erat kaitannya dengan obturasi saluran akar yang baik serta menempatkan barier atau pelapis servikal yang benar, untuk menghindari pengaruh merugikan yang mungkin terjadi. 


\section{DAFTAR PUSTAKA}

1. Patil R. Esthetic dentistry: An artist's science. Mumbai: PR Publication; 2002. p. 83-91.

2. Halim HS. Perawatan Diskolorisasi gigi dengan tehnik bleaching. Edisi ke 1. Jakarta: Penerbit Usakti; 2006.5-6.

3. Walton R E, Torabinejad M. Prinsip dan Praktik Ilmu Endodonsia. Alih bahasa: Yuwono L. Edisi ke-3. Jakarta: EGC; 2008.p.455-460.

4. Robert HD, Yudha R, Irene D. Dental Whitening. Jakarta: PT. Dental Lintas Media; 2005.p.9.
5. Ingle JI, Bakland LK. Endodontics. $6^{\text {th }}$ Ed. Ontario: BC Decker Inc.P.; 2008. p. 1389.

6. Greenwall L, ed. Bleaching techniques in restorative dentistry. New York: Thieme; 2001. p. 159.

7. Plotino G, Buono L, Grande NM, Pameijer $\mathrm{CH}$, Somma F. Nonvital tooth bleaching: a review of the literature and clinical procedures. J Endodont 2008; 34(4): 394-407.

8. Dahl JE, Pallesen U. Traumatic injuries to the teeth. $4^{\text {th }}$ Ed. Munksgaard: Blackwell; 2007. p. 853. 